\title{
Development of sugar free cookies with novel biodegradable packaging film
}

\section{Eram S. Rao}

Department of Food Technology, Bhaskaracharya College of Applied Sciences, University of Delhi, New Delhi-110075, India

\section{Prem Lata Meena}

Department of Polymer Science, Bhaskaracharya College of Applied Sciences, University of Delhi, New Delhi-110075, India

Manjeet Singh Barwa*

Department of Chemistry, Bhaskaracharya College of Applied Sciences, University of Delhi, New Delhi-110075, India

*Corresponding author. Email: manjeetbarwa@gmail.com

\section{Article Info}

https://doi.org/10.31018/ jans.v13i1.2532

Received: January 28, 2021

Revised: March 7, 2021

Accepted: March 11, 2021

\section{How to Cite}

Rao, E. S. et al. (2021). Development of sugar free cookies with novel biodegradable packaging film. Journal of Applied and Natural Science, 13(1): 316 - 326. https://doi.org/10.31018/jans.v13i1.2532

\begin{abstract}
The use of alternative sweeteners can help manage weight and normal blood glucose levels of diabetics. Development and standardization of sugar free, low glycemic index and high fibre cookies using wheat flour, oats, trans free bakery shortening, and almonds. Physiochemical analysis of the raw materials used for cookie preparation and the finished product was conducted. Cookies were analysed for diameter, height, spread ratio, texture, and water activity. Sensory analysis using semitrained panellists was done to establish the acceptability of the product. The formulated cookies were well accepted by the semitrained panellists as well as the people with diabetes who were randomly selected for the study. The overall appearance, texture and flavour of the cookies were moderately liked by the panellists as indicated in the qualitative descriptive analysis. The product did not change much with the storage of 90 days. The cookies were high in dietary fibre $(2.5 \mathrm{~g}$ per serving), out of which $\beta$ - glucan, a soluble fibre was found to be $0.8 \mathrm{~g}$ per serving which offers a healthy alternative for consumers. The biodegradable polymer used for packaging the cookies was prepared using terpolymer. The chemical and physical properties of the polymer were determined using acid value which was between 0.0195 and 0.0200 , hydroxyl value; 0.0260 and 0.023 and the molecular weight was in the range of $10,256 \delta$ and $10,000 \delta$ of the terpolymer $A$ and $B$, respectively. The polymer demonstrated good mechanical strength as well as and water vapours barrier properties to be used as a primary package for cookies.
\end{abstract}

Keywords: Glycemic Index, High Fiber, Diabetics, biodegradable, packaging

\section{INTRODUCTION}

India has been recently declared as the 'diabetic' capital of the world. One in every five persons in India suffers from diabetes and other related disorders (Joshi et al., 2005). According to the International Diabetes Federation (Diabetes Atlas ninth edition, 2019) an estimated 463 million (9.3\%) adults aged $20-79$ years are currently living with diabetes. This number is predicted to rise to 578 million (10.2\%) by 2030 and to 700 million $(10.9 \%)$ by 2045 . People suffering from diabetes are advised to restrict their use of sugars. (Aggarwal, et al., 2016) The use of alternative sweeteners can help manage weight and normal blood glucose level (Deshmukh, et al., 2019).
Cookies have gained popularity amongst consumers due to their ease in availability, affordability, varietal flavours, and light texture. They are shelf-stable, ready to eat, wholesome, nutritious snacks with enhanced value addition. However, due to the growing health consciousness of the consumers, foods containing high amount of sugar and fat with high glycemic index (GI) may predispose them to overweight and obesity. (Handa et al., 2012). Nowadays, cookies made from oats are much in demand because of their enhanced functional properties. Oats are rich in dietary fibre, specifically, $\beta$-glucan, which is a soluble fibre, known to reduce blood cholesterol level by increasing the excretion of bile in the body (Jenkis and Kendal 2002). In addition to this it is also high in proteins, minerals such 
as iron and magnesium and pantothenic acid $\left(B_{5}\right)$. There is also an increasing demand for products with reduced energy, especially those that use sweeteners as substitutes for sucrose (Trevizian et al., 2010). Substituting sugar with low-calorie sweeteners may be an efficacious weight management strategy.

Sugar plays a significant role in providing golden brown colour, pleasant aroma, crumb structure and overall acceptability to the baked products. But due to the increase in the prevalence of non- communicable diseases at an alarming rate such as diabetes, obesity, dental caries and cardiovascular diseases, nowadays, non nutritive intense artificial sweeteners are being used as substitutes for developing sugar-free products by the food industry. (Aggarwal, D. et al.,2016) Substitution of artificial sweeteners with sucrose may facilitate the maintenance of nutritionally balanced diet by satisfying a diabetic person's desire for sweets and assist in the control of calorie intake (Chattopadhyay et al., 2014).

However, the use of artificial sweeteners poses technological challenges to the food processor during baking. The crucial functions of sucrose in foods are not easy to mimic by its replacers. Substitution of sugar with intense non-nutritive sweeteners affects the physiochemical properties of baked products. Partial replacement of sugar in muffins with intense sweeteners along with inulin was done to achieve desired structure and sweetness. (Gao et al., 2018).

Several studies have been conducted to study the effect of sugar substitution with artificial sweeteners on the quality of cookies (Savitha et al. 2008). Sucralose has been reported to have excellent product stability even when subjected to high temperatures during baking. Sugar alcohols have been suggested as bulking agents for the low- calorie baked goods, as intense sweeteners lack texture modifying property like sucrose. Polyols such as sorbitol, maltitol, xylitol etc. have been employed in the manufacture of sugar-free candies, cookies and chewing gums in the industry. (Zoulas et al., 2000). Therefore, the present study was undertaken to provide consumers with healthy food choices and help in the management of noncommunicable diseases such as diabetes mellitus, obesity and cardiovascular diseases.

In India, biodegradable polymeric films which are economical as well as eco-friendly are in great demand. Plastic is synthetic polymer which is used in the entire world due to its mechanical properties, long durability and its cost effectiveness but its properties like biodegradation resistant, its inertness and hard to degrade and obvious human behaviour of littering plastic are the major consequences for the need of biodegradable plastic. Most of the plastics in the market claimed to be biodegradable are based on synthetic and microbial polyesters. Different degradable polymers such as polylactides, poly ethylene-carbon monoxide polymers (3- hydroxybutyrate-3-hydroxyl valerate), vinyl ketone copolymers (Guillet process), and starch-filled polyethylene (Griffin process), have been developed. These plastics differ in degradation rate, application, and price. (Muller et al., 2001) has reported that plastic inertness and resistance to microbial attack was reduced by incorporating starch and pro-oxidants. The aromatic polyesters such as polyethylene terephthalate and polybutylene terephthalate have excellent material properties as compared to most aliphatic polyesters and also their susceptibility to microbial attack is negligible. Therefore, to increase the biodegradability of aromatic polyesters, some studies focused on the synthesis of aliphatic-aromatic copolyesters or incorporation of aliphatic dicarboxylic acids or polyethylene glycol in polyester chains which greatly enhance the degradation rate (Gnanavel et al., 2012).

Among these polymers much progress has been made in polylactic acid (PLA), Polyglycolic acid (PGA) and their copolymers. These can be synthesized in wide range of molecular weights by two methods; through direct condensation reaction of lactic acid/ or glycolic acid which leads to low molecular weight and secondly, by ring opening polymerization of cyclic dimer i.e. lactide and glycolide, in the presence of metal catalyst to synthesize high molecular weight polymers (Lindani et al., 2020). Therefore, in the present study, an attempt was made to prepare a novel thermoplastic polymer using the poly-condensation approach to produce terpolymer of lactic acid, phthalic anhydride and ethylene glycol. This biodegradable packaging material was also studied for tensile strength and water vapour transmission rate.

\section{MATERIALS AND METHODS}

\section{Raw material source and analysis}

Whole wheat flour and rolled oats were procured from the local Delhi market. Bakery shortenings which were trans-fat free was obtained from Cargill Foods Delhi, India. Sucralose (sugar free - cadillazydus) was selected and purchased on the basis that it is approved for food use by FSSA, 2006 and is heat stable during baking. Vanilla essence, baking powder, almonds were also procured from the local market of Delhi. All raw materials were analysed for physical and chemical quality as per AOAC (1998) procedures to ensure the good quality of the finished products (Table 1).

\section{Physical analysis}

Wheat flour and oats were analyzed physically on the basis of its colour, feel/ texture and insect infestation.

\section{Chemical analysis}

Determination of moisture content, ash content, water absorption power, gluten content, sedimentation value 
Rao, E. S. et al. / J. Appl. \& Nat. Sci. 13(1): 316 - 326 (2021)

was done for wheat flour and moisture content and total ash for oats was done, respectively.

\section{Proximate analysis of cookies}

It included determination of moisture, protein, fat, dietary fibre and ash content.

\section{Microbiological analysis}

Total Plate Count (TPC) and E. coli

\section{Sensory analysis \\ Cookie formulation}

Short dough cookies were prepared as per the AOAC method (2004) with some modifications by creaming bakery shortening with sucralose a non- nutritive sweetener and vanilla essence until pale and fluffy using planetary mixer (Moulinex, Masterchef compact) at speed 2 for 5 minutes (Table 2). Refined flour was sifted with baking powder and salt and then stirred until well mixed. Rolled oats, almonds were incorporated. Standardized amount of water was added and the dough was kneaded for 5 minutes. The cookie dough was wrapped in plastic wrap to prevent moisture loss and kept in the refrigerator for an hour. The dough was tempered to room temperature $\left(21^{\circ} \mathrm{C}\right)$ and scooped

Table 1. Chemical analysis of raw materials used for preparation of cookies.

\begin{tabular}{|c|c|c|c|c|}
\hline & $\begin{array}{l}\text { Wheat } \\
\text { Flour }\end{array}$ & Oats & $\begin{array}{l}\text { Fatty acid } \\
\text { profile of } \\
\text { bakery fat }\end{array}$ & \\
\hline $\begin{array}{l}\text { Moisture } \\
\text { content }\end{array}$ & $12.29 \%$ & $11.32 \%$ & $\begin{array}{l}\text { Free fatty } \\
\text { acids as } \\
\text { oleic acid }\end{array}$ & $0.05 \%$ \\
\hline Ash content & $1.16 \%$ & $0.54 \%$ & $\begin{array}{l}\text { Peroxide } \\
\text { value }\end{array}$ & 0.76 \\
\hline $\begin{array}{l}\text { Acid insoluble } \\
\text { Ash content }\end{array}$ & $0.13 \%$ & & & \\
\hline $\begin{array}{l}\text { Water absorp- } \\
\text { tion power }\end{array}$ & $60 \%$ & & lodine Value & 44.68 \\
\hline $\begin{array}{l}\text { Sedimentation } \\
\text { value }\end{array}$ & $30 \mathrm{ml}$ & & Melting point & $40.5^{\circ} \mathrm{C}$ \\
\hline $\begin{array}{l}\text { Gluten } \\
\text { content (wet) }\end{array}$ & $2.373 \mathrm{~g}$ & & & \\
\hline
\end{tabular}

Table 2. Ingredients used for cookies.

\begin{tabular}{ll}
\hline Ingredients & Amount (g) \\
\hline Wheat Flour & 150 \\
Oats & 115 \\
NNS & 5 \\
Bakery Shortening & $115^{\star}$ \\
Vanilla extract & $1 \mathrm{tsp}$ \\
Salt & 2.5 \\
Baking powder & 2.5 \\
Almonds & 115 (chopped) \\
Water & $60 \mathrm{ml}$ \\
Milk solids & 30 \\
\hline
\end{tabular}

with an ice cream scooper before being dropped on the baking sheets to be baked for 30 minutes in a preheated oven at $180{ }^{\circ} \mathrm{C}$. The cookies were allowed to cool for $1 \mathrm{hr}$ at ambient temperature. The cookies were stored at room temperature $\left(22-24^{\circ} \mathrm{C}\right)$ and sensory and instrumental evaluations were performed.

\section{Physical evaluation of cookies \\ Cookie diameter, height and spread ratio}

Cookie diameter $(\mathrm{cm})$ was measured by laying six cookies edge to edge with the help of scale and then rotating them by $90^{\circ}$ and re-measuring. The average diameter of the cookies was the average of the two readings divided by six. Cookie height $(\mathrm{cm})$ was determined by stacking six cookies on top of one another, restacking and re-measured. The average height of the cookies was the average of the two readings divided by six. Spread ratio, which is defined as a ratio of average diameter to an average height of the cookies, was then calculated.

\section{Instrumental analysis}

Cookie texture: A texture analyser (TA-XT Plus), Stable Microsystems, UK equipped with a $50 \mathrm{~kg}$ load cell was used for cookie texture evaluation. Cookies were evaluated for hardness within $24 \mathrm{~h}$. The cutting strength was measured using HDP/BS blade of texture analyzer. The individual samples of biscuits were placed on the platform and the blade was attached to the crosshead of the instrument. The TA settings selected were pre- test speed: $2 \mathrm{~mm} / \mathrm{s}$, test speed: $3 \mathrm{~mm} / \mathrm{s}$, post- test speed: $10 \mathrm{~mm} / \mathrm{s}$ and distance $5 \mathrm{~mm}$. The absolute peak force of the resulting curve was considered as the cutting strength of the biscuit (Fig. 1).

Water activity: Water activity $\left(A_{w}\right)$ of cookie samples was measured with a water activity meter (Aqua Lab model DTE) Decagon Devices Inc., Pullman, WA. It was calibrated with sodium chloride standard solution (6 molal, at $25 \mathrm{C}, \mathrm{A}_{\mathrm{w}}=0.7549$, Decagon devices). A 30 $\mathrm{mm}$ diameter round plug was punched from the centre of each cookie and crumbled inside the sample cup, and inserted into the metering chamber. The $A_{w}$ was measured using the chilled- mirror method at sample temperature set to $25+-0.2{ }^{\circ} \mathrm{C}$. The measurements were replicated three times.

\section{Sensory acceptability tests Panel training}

Forty five students were randomly selected based on their willingness to participate in the sensory training and study. The panel members were Food Technology students pursuing graduation at Bhaskaracharya College of Applied Sciences, University of Delhi, New Delhi, India. The panellists were between 18- 20 years of age and were regular consumers of cookies. They were given a series of psychometric tests which includ- 


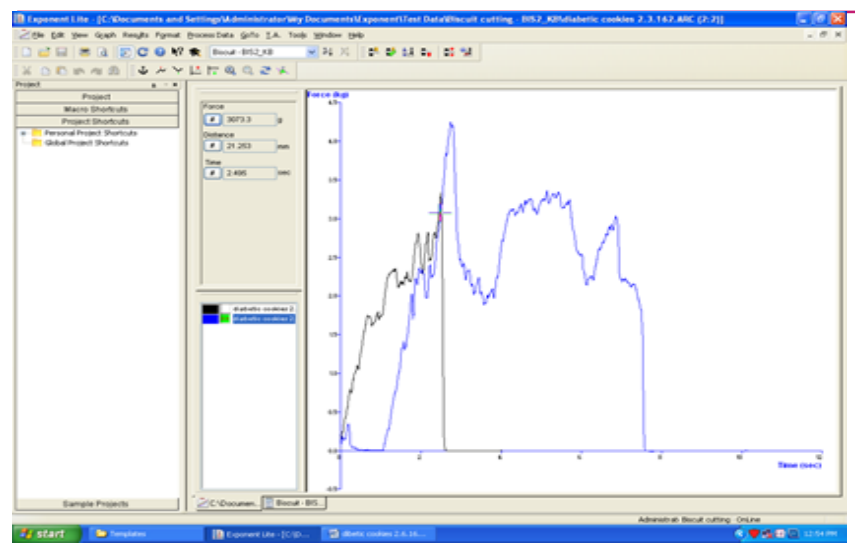

Fig. 1. Curves depicting the cutting strength of cookies using TAXT PLUS Texture analyser.

ed; recognition threshold, sensitivity test and PTC test. Fifteen students were included in the semi trained panel based on their sensitivity and only tasters were selected. In the preliminary session panellists were trained for sensory evaluations; care was taken to avoid physiological errors and bias. They were then trained for threshold study and Quantitative Descriptive Analysis (QDA) (Table 3).

\section{Psychometric studies Threshold study}

A threshold test for the sugar and intense sweeteners was conducted based on the method given in IS: 5126 (1969) and ASTM 1996. Stock solutions of sugar and intense sweeteners were prepared for the threshold test. From the $1 \%$ stock solution of sucrose, a series of dilutions were made representing increasing sweetness concentration. Initially, geometric series was prepared for deciding the concentration for arithmetic series ranging from 0.4 to $2 \%$ for sucrose and evaluated by trained panellists. The series for other sweeteners were sucralose $(0.001$ to $0.005 \%)$ and stevia (0.01 to 0.1$)$. These dilutions of sugar and sugar substitutes had a different intensity of sweetness. The panellists were asked to taste the series of solutions arranged in increasing order of concentrations and mark ' 0 ' if no stimulus was perceived, '?' if the stimulus was perceived to be different from blank but not recognizable and ' $x$ ' for recognition threshold value for sweetness.

\section{Cookie storage studies}

Sugar-free cookies were packed in individual cups made of biodegradable terpolyster and then in $100 \mathrm{gms}$ non-leachable pouches comprising of a two-layered laminated material made up of metallized $P E$ and LDPE nylon with GSM of $75 \mathrm{~mm}$. The final product was stored at different temperatures and relative humidity to check the stability of the product (Table 4). The stability conditions were decided on the basis of intrinsic and extrinsic factors of the product. The storage studies for diabetic cookies were conducted for three months at
Table 3. Sensory attributes of cookies using quantitative descriptive analysis.

\begin{tabular}{l}
\hline Appearance \\
\hline Visible Choco chips- Amount of chips visible from few too \\
many. \\
Colour intensity- Intensity of brown colour, from buff \\
(light brown to dark brown) \\
Uniformity of colour- Uneven to even \\
Surface cracks- Visible surface cracks on cookie- from \\
none to many. \\
\hline Aroma \\
\hline Chocolaty- from none to strong \\
Baked flavour- Pleasant aroma of baked cookies from \\
none to strong
\end{tabular}

Flavour

Sweet- The sweet taste of the tongue, from low (5\%) to high $(25 \%)$

Chocolaty- The taste of chocolate morsel on tongue from none to strong

Oaty- The taste of oatmeal, from none to strong

\section{Texture}

Dryness- The amount of saliva absorbed by sample, from moist to dry

Hardness- Force required to break a sample into two pieces in mouth, from soft to hard

Graininess- Amt of sample particles in the mouth after chewing, from none to many

Denseness- Compactness of cross section after first bite, from airy to dense

Crumbliness- At first bite, sample stay in big pieces (not crumbly), or sample breaks into crumbs (very crumbly)

\section{Aftertaste}

Sweet- Sweetness lingering in the mouth after swallowing, from none to strong

Chocolaty- Chocolate flavour lingering in the mouth after swallowing; the aftertaste of chocolate morsel, from none to strong

Metallic- metal like flavour lingering in the mouth after swallowing from none to strong

ambient temperature that is $27^{\circ} \mathrm{C}$ and $40^{\circ} \mathrm{C} \pm 2^{\circ} \mathrm{C}$ and relative humidity of $75 \% \pm 5 \%$ respectively. They were analysed on the zero day, third day, seventh day and then fortnightly for 90 days. During this period, the cookies were analysed for physicochemical, microbiological and sensory parameters. (Table 5).

\section{Macro nutritive composition of cookies}

Macro nutritive composition of cookies included estimation of moisture, total fat, cholesterol, trans fat, protein, total carbohydrate, dietary fibre, calcium, iron, ash, and vitamin A. Moisture content of the cookies (\%) was done using the air oven drying method (AOAC: 2005) $\left(105 \pm 1^{\circ} \mathrm{C}\right.$ for $4 \mathrm{~h}$ ), fat estimation using soxhlet extraction, protein using Kjeldhal method, total dietary fibre using AOAC 991.43:2005, ash content (AOAC: 2005) and carbohydrates (by difference) content of cookies 
Rao, E. S. et al. / J. Appl. \& Nat. Sci. 13(1): 316 - 326 (2021)

Table 4. Sensory evaluation of diabetic cookies.

\begin{tabular}{|c|c|c|c|c|}
\hline Panellists & $\begin{array}{l}\text { Code } 1 \\
\text { Control }\end{array}$ & $\begin{array}{l}\text { Code } 2 \\
\text { (Fresh finished } \\
\text { product) }\end{array}$ & $\begin{array}{c}\text { Code } 3 \\
\text { (after two months of opening } \\
\text { the product) }\end{array}$ & $\begin{array}{c}\text { Code } 4 \\
\text { (after three months of opening the } \\
\text { product) }\end{array}$ \\
\hline 1 & 8 & 5 & 8 & 5 \\
\hline 2 & 8 & 6 & 7 & 8 \\
\hline 3 & 2 & 6 & 8 & 5 \\
\hline 4 & 8 & 7 & 7 & 6 \\
\hline 5 & 8 & 5 & 6 & 5 \\
\hline 6 & 7 & 5 & 6 & 6 \\
\hline 7 & 8 & 6 & 7 & 7 \\
\hline 8 & 7 & 3 & 8 & 8 \\
\hline 9 & 8 & 6 & 6 & 6 \\
\hline 10 & 8 & 6 & 7 & 7 \\
\hline Average & 8 & 7 & 5.2 & 6 \\
\hline SD & 2.4 & 1.41421356 & 1.32664992 & 1.5494 \\
\hline
\end{tabular}

Table 5. Physico-chemical, microbiological and sensory analysis of cookies.

\begin{tabular}{llllll}
\hline Method/ parameters & Specifications & O Days & 1 Month & 2 Months & 3 Months \\
\hline Sensory analysis & Crispy texture and flavour & No Rancidity & No Rancidity & No Rancidity & No Rancidity \\
& Moisture content $\%$ & 2.08 & 2.10 & 2.35 & 2.50 \\
Physio- Chemical & Water Activity & 0.4785 & 0.4418 & 0.5148 & 0.4086 \\
analysis & Sensory & Acceptable & Acceptable & Acceptable & Acceptable \\
& Rancidity & Absent & Absent & Absent & Absent \\
Microbiological & Total Plate count $(10,000 / \mathrm{ml})$ & NIL & NIL & NIL & 15 \\
analysis & E. Coli $(\mathrm{cfu} / \mathrm{ml})$ & Absent & Absent & Absent & Absent \\
& Yeast and Mold $(\mathrm{cfu} / \mathrm{ml})$ & Absent & Absent & Absent & Absent \\
\hline
\end{tabular}

were determined.

\section{Method for synthesis of biodegradable packaging Reagent source and analysis}

All the reagents, lactic acid (AR), phthalic anhydride, ethylene glycol and stannous chloride, were procured either from E. Merck or Thomas Baker. All the glassware which were used for the laboratory purpose were kept overnight in a $10 \%(\mathrm{v} / \mathrm{v})$ nitric acid solution and distilled water was used to wash the glassware.

\section{Synthesis of terpolyester}

The condensation reaction occurs in two steps. The first step is poly-esterification followed by polycondensation reaction. Lactic acid, phthalic anhydride and ethylene glycol were taken in proportion of $0.3: 1: 1$ in a three necked round bottom flask. A thermometer was fitted to the neck, a stirrer to the other and DeanStark was fitted to third neck as shown in Fig. 2.

At first, the temperature was maintained at $140{ }^{\circ} \mathrm{C}$ for 7 $\mathrm{h}$ and then with constant stirring, the reaction was carried out at $200^{\circ} \mathrm{C}$ for $10 \mathrm{~h}$ and $0.5 \%$ stannous chloride was added as a catalyst. The mixture was then poured into a petri dish with a silica gel coating and cooled as shown in Fig. 3. The film is formed polymer is melted in the presence of lactic acid $(0.4 \mathrm{~mol})$ phthalic anhydride $(1.0 \mathrm{~mol})$ and ethylene glycol $(1.0 \mathrm{~mol})$. This is done in three-necked round bottom flask. (Jaemin et al., 2020)

\section{Characterization of terpolyester resin}

The synthesized terpolyester so obtained were characterized for acid value, hydroxyl value, no. average molecular weight, UV-Vis Spectroscopy, FT-IR and ${ }^{1} \mathrm{H}$ NMR.

\section{Acid value (ASTM D 1639)}

Acid number was determined by dissolving $2.5 \mathrm{~g}$ polymeric material in chloroform and was titrated against $0.1 \mathrm{~N}$ of standardized $\mathrm{KOH}$ until endpoint persisted. Phenolphthalein was used as indicator. End point was pink color.

$$
\text { Acid Value }=\frac{5.61 \times \mathrm{V} \times \mathrm{N}}{\mathrm{M}}
$$

Where $\mathrm{V}=\mathrm{Vol}$. of $\mathrm{KOH}, \mathrm{N}=$ Normality of $\mathrm{KOH}$ and $\mathrm{M}=$ mass of polymer dissolved

Approx. $0.50 \mathrm{~g}$ of polymer was taken in $50 \mathrm{ml}$ phthoylating mixture and hydrolysed by adding $100 \mathrm{ml}$ chilled $\mathrm{DI}$ water in another flask. Under vigorous stirring, $20 \mathrm{ml}$ benzene was added. The resulting solution was titrated 

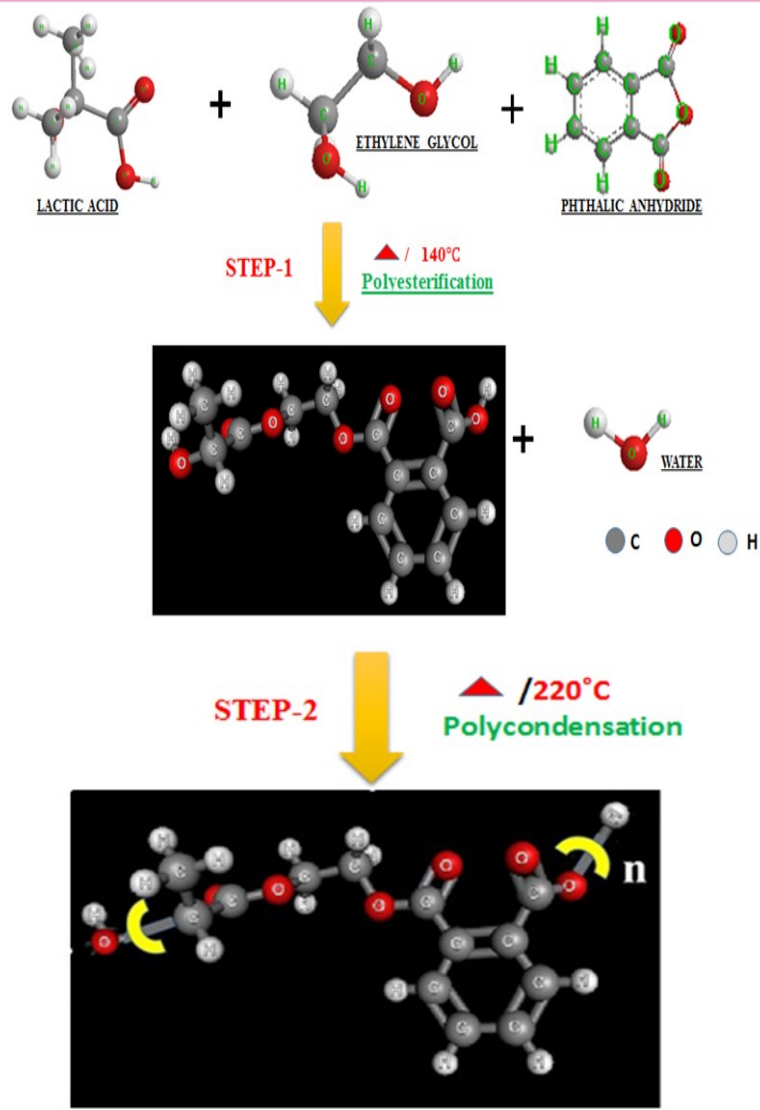

Reactions involved in synthesis of Terpolyester

Fig. 2. Synthesis of terpolyester.

against $0.5 \mathrm{~N}$ standardized $\mathrm{KOH}$ using phenolphthalein as indicator.

$$
\text { Hydroxyl value }=\frac{56.1(\mathrm{v} 1-\mathrm{V} 2) \times \mathrm{N}}{\mathrm{m}}
$$

Where $\mathrm{V}_{1}=$ vol. of $0.5 \mathrm{KOH}$ used in blank titration, $\mathrm{V}_{2}=\mathrm{vol}$. of $0.5 \mathrm{KOH}$ used for polymer solution

The no. average molecular weight was calculated using the following expression:

$$
\mathrm{Mn}=\frac{\mathrm{F} \times 100}{\mathrm{C}}
$$

Where $\mathrm{F}=$ functionality of Polymer \& $\mathrm{C}=$ Acid value

The UV-Vis spectroscopy of terpolyester was done using ELCO SL 159 and determined the maximum absorption by using solvent chloroform. The maximum absorption of UV of both the terpolyester occur at 205 $\mathrm{nm}$ with different intensities. Ratio 0.3:1:1 with intensity 0.981 and ratio $0.4: 1: 1$ with 0.875 . The UV-Vis spectroscopy study of terpolyester concluded that there is a transition due to carbonyl chromophore present in the structure. It shows there is a transition in $\mathrm{nm}^{*}$.

\section{RESULTS AND DISCUSSION}

In present study, the formulated cookies were sugar free, high in soluble fibre $\beta$ - glucan and had a low glycemic index $(\mathrm{Gl})$. This technology has been developed

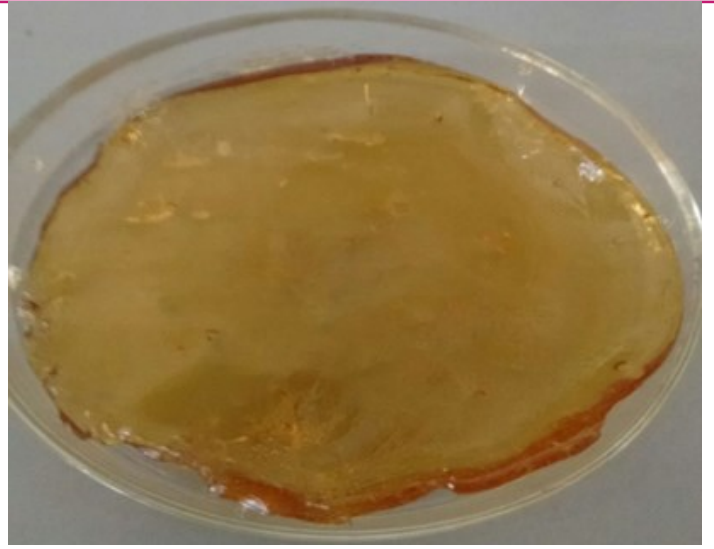

Fig. 3. Petri plate showing the polyester film.

at lab scale keeping in mind the consumer's interest in health and special dietetic foods.

\section{Raw material analysis}

The chemical analysis of the raw material used for the preparation of the cookies is tabulated as under.

\section{Physical evaluation of cookies Cookie diameter}

Cookies made with non-nutritive sweetener were found to have an average diameter of $4.91 \mathrm{~cm}$. This could be attributed to a lack of sugar content and high fibre content from oats and bran in the cookies. Deshmukh and Bhivagade 2019 reported a decrease in the diameter of biscuits made with $3 \%$ sucralose and $0.1 \%$ stevia. The decrease in the diameter of the cookies usually occurs during baking due to the production of carbon dioxide by leavening agents and water evaporation. (Faridi et al., 1994). However, cookies made with natural sweetener, i.e. $100 \%$ sucrose have been reported to have an average diameter of $5.5 \mathrm{~cm}$ (Stone and Sidel, 1998).

\section{Cookie height}

The cookie height is attributed to gluten development during the baking process. The sugar competes for water over gluten proteins and therefore, the increase in the height of the cookies takes place gradually. Thus, the quantity and kind of sugar used in the formulation directly influence the height of cookies. The mean height of cookies made with non-nutritive sweetener was $2.58 \mathrm{~cm}$ as compared to those made with $100 \%$ sucrose which was reported to be $1.25 \mathrm{~cm}$. This is because of the lack of hygroscopic nature of non-nutritive sweetener, sucralose that does not compete for water and allows for greater hydration of gluten and heightens the cookies (Handa et al., 2012). Similar observations were made by Deshmukh and Bhivagade (2019) with an increase in the height of biscuits prepared with sucralose and stevia from 4 to $6 \mathrm{~mm}$. Further, the shortening used for sugar-free cookies had nitrogen flushing, which could be responsible for the increased 
Rao, E. S. et al. / J. Appl. \& Nat. Sci. 13(1): 316 - 326 (2021)

height.

\section{Cookie spread ratio}

This is the ratio of diameter to height or thickness of a cookie. The diameter of the cookie is directly influenced by the behaviour of sugar when it dissolves and the height when it resists gluten development. Both these parameters are combined into one. Cookies with a high spread ratio are considered most acceptable.

The spread ratio of high fibre oatmeal cookies made with non-nutritive sweetener was 1.90. Spread ratio of sugar-free multigrain biscuits made with ragi flour was reported to be more than soy flour by Deshmukh and Bhivagade (2019). These findings are also supported by Sudha et. al. (2007) study in which the incorporation of different sources of bran showed opposite relations with spread ratio. The spread ratio of the biscuits prepared from wheat, rice and oat bran blends decreased from 8.38 to 7.52 , whereas the same increased to 9.3 for biscuits prepared from barley bran blends.

\section{Cookie texture}

The cutting strength of sugar-free cookies made with sucralose had lower hardness with a mean peak force of $3073.3 \mathrm{~g}$, which is considered a desirable characteristic as depicted in Fig. 4. Deshmukh and Bhivagade (2019) reported decreased hardness and softer texture of multigrain biscuits made with sucralose and stevia as compared to the control which showed high value of peak force. Handa et al. (2012) also reported a similar observation, with higher mean peak force of $7139 \mathrm{~g}$ for cookies made with $100 \%$ sucrose.

\section{Water activity}

The shelf stability and safety of the product is determined in terms of its water activity which is responsible for microbial growth. Although cookies are low in moisture content, but they are susceptible to the growth of moulds and yeast which can grow above 0.61 (Fontana,2000). The average $a_{w}$ of sugar free cookies with sucralose was found to be 0.46 . The $a_{w}$ of cookies was found to be slightly higher as compared to cookies made exclusively with sucrose because of its high fibre content. It has been reported by Manley et al., 2000) that the soluble fibre, $\beta$ - glucan present in oats could hold water at higher temperatures associated with baking.

\section{Sensory acceptability tests}

The results of the descriptive analysis of the cookies are shown in Fig. 4. The overall acceptability was found to be $60 \%$ by the panellist for cookies with sucralose, having a mean score of 5.7 on a 9 point hedonic scale. The cookies were brown in colour and had pleasant flavour, and sweetness without lingering after the taste of the sweetener. The texture was found to be acceptable but grainy because of the presence of wheat bran and rolled oats. Crumbliness which is a desirable property of cookies, was reported to be 6.33 on a nine-point scale. The visual appearance of the cookies with nonnutritive sweetener was also liked moderately.

The overall acceptability of developed formulations was higher in the rating of liking that is between 7-8. The product did not change much with the storage of 90 days at ambient temperature, as depicted in Table 3. However, a consistent decline in the overall acceptability of the product was reported by the judges as compared with the control product after two months and then after three months.

\section{Cookie storage stability studies Cookie moisture content}

The moisture content of the cookies was found to be $2.08 \%$ at 0 month and $2.50 \%$ at the end of the third month. There was no significant increase in moisture content during the storage period of the study and was found in the acceptable limit as given by FSSAI of less than 5\%. (Deshmukh and Bhaivagade, 2019) also reported a similar increase in moisture content from an initial $4.4 \%$ to $4.69 \%$ at the end of two months of sugar -free multigrain biscuits prepared with sucralose and stevia when stored for two months.

\section{Physico-chemical, microbiological and sensory studies \\ Stability studies of the product}

The accelerated shelf-life studies were carried out for sugar-free cookies after packaging in biodegradable polymer for a period of 90 days, as shown in Table 6 . The microbiological studies conducted for yeast, mold, total plate count and coliform revealed that no microbial growth was detected in sugar-free cookies till the end of storage period. Thus, the product is safe to consume.

\section{Macro nutritive composition of cookies}

Nutritional evaluation of cookies prepared with nonnutritive sweetener is shown in Table 7. The sugar-free cookies provided a high fibre content of $8.3 \mathrm{~g}$ per 100 gms with zero trans fats. The cookies had a low glycemic index with high dietary fibre content of $2.5 \mathrm{~g}$ per serving, out of which $\beta$-glucan, a soluble fibre was found to be $0.8 \mathrm{~g}$ per serving. Thus, offering a healthy alternative for consumers.

\section{Chemical analysis of synthesized terpolyester}

The acid value, hydroxyl value and molecular weight of the synthesized terpolyester denotes good barrier properties and optimum mechanical strength as required by any packaging film as shown in Table 8 . 
Rao, E. S. et al. / J. Appl. \& Nat. Sci. 13(1): 316 - 326 (2021)

Table 6. Microbiological analysis of accelerated shelf-life stability data of cookies.

\begin{tabular}{llllllll}
\hline & $\mathbf{1 s t}^{\text {t }}$ Day & $\mathbf{3}^{\text {rd }}$ Day & $\mathbf{7}^{\text {th }}$ Days & $\mathbf{1 5}^{\text {th }}$ Days & $\mathbf{3 0}^{\text {th }}$ Days & $\mathbf{6 0}^{\text {th }}$ Days & $\mathbf{9 0}^{\text {th }}$ Days \\
\hline $\begin{array}{l}\text { Total Plate Count } \\
\text { cfu/ml) }\end{array}$ & Nil & Nil & Nil & Nil & Nil & Nil & 15 \\
$\begin{array}{l}\text { Yeast and Mold } \\
\text { (cfu/ml) }\end{array}$ & Nil & Nil & Nil & Nil & Nil & Nil & Nil \\
E.Coli $(\mathrm{cfu} / \mathrm{ml})$ & Nil & Nil & Nil & Nil & Nil & Nil & Nil \\
\hline
\end{tabular}

Table 7. Nutritive value of diabetic cookies.

\begin{tabular}{llc}
\hline & & Serving Size: 1 cookie (30 g approx.) \\
\cline { 2 - 3 } Energy, Kcal & $\begin{array}{c}\text { per } \mathbf{1 0 0 ~} \mathbf{~ g} \\
\mathbf{5 0 0} \mathbf{~ k c a l}\end{array}$ & $\begin{array}{l}\text { per serving } \\
\mathbf{1 5 0} \mathbf{~ k c a l}\end{array}$ \\
\hline Calories from Fat & 222 & 67 \\
Total Fat & $25 \mathrm{~g}$ & $7.5 \mathrm{~g}$ \\
Saturated Fat & $11 \mathrm{~g}$ & $3.3 \mathrm{~g}$ \\
Trans Fat & $0 \mathrm{~g}$ & $0 \mathrm{~g}$ \\
Cholesterol & $0 \mathrm{~g}$ & $0 \mathrm{~g}$ \\
Sodium & $63 \mathrm{mg}$ & $19 \mathrm{mg}$ \\
Total Carbohydrate & $61 \mathrm{~g}$ & $18 \mathrm{~g}$ \\
Dietary Fibre & $8.3 \mathrm{~g}$ & $2.5 \mathrm{~g}$ \\
Sugar as Sucrose & 0 & $0 \mathrm{~g}$ \\
Protein & 14 & $4.2 \mathrm{~g}$ \\
Vitamin A & $33.3 \mathrm{IU}$ & $9.9 \mathrm{IU}$ \\
Calcium & $16.6 \mathrm{mg}$ & $5 \mathrm{mg}$ \\
Iron & $5.5 \mathrm{mg}$ & $1.6 \mathrm{mg}$ \\
\hline
\end{tabular}

Table 8. Chemical analysis of the synthesized terpolymers.

\begin{tabular}{lllll}
\hline $\begin{array}{l}\text { Name of } \\
\text { Terpolymers }\end{array}$ & Ratio & Acid Number & Hydroxyl Value & $\begin{array}{l}\text { Number Average Molecular } \\
\text { Weight }\end{array}$ \\
\hline (A) LA:EG:PA & $0.3: 1: 1$ & 0.0195 & 0.026 & 10,256 \\
(B) LA:EG:PA & $0.4: 1: 1$ & 0.0200 & 0.023 & 10,000 \\
\hline
\end{tabular}

(Lindani et al., 2020) reported that the molecular weight of the polymer was lower as compared to the terpolyester in the present study which was found to be more than 10,000. This signifies the good mechanical strength properties of the polymer.

\section{Infrared spectroscopy}

Infrared spectroscopy indicated the presence of ester bond and aromatic hydrocarbons. The sharp peak obtained at $1716 \mathrm{~cm}^{-1}$ indicated $\mathrm{C}=\mathrm{O}$ in aryl ester. The broad peak at $3447 \mathrm{~cm}^{-1}$ indicates presence of $\mathrm{O}-\mathrm{H}$ structure of alcohol and the presence of two bands at 1134 and $1281 \mathrm{~cm}^{-1}$ indicates the presence of $\mathrm{C}-\mathrm{O}$ in ester. The bands at $1507 \mathrm{~cm}^{-1}$ and $1575 \mathrm{~cm}^{-1}$ indicate $\mathrm{C}=\mathrm{C}$ structure in aromatic hydrocarbon, as shown in Fig. 5. The presence of aromatic hydrocarbons implicate a rigid structure of the polymer. This a desirable feature in the production of packaging materials. It has been seen that formation of aliphatic hydrocarbons are responsible for a weak esterification of polymers.

\section{UV-Vis spectroscopy}

The maximum absorption of UV of both the terpolyesters occurred at $205 \mathrm{~nm}$ with different intensities. The ratio of terpolyester $A$ was $0.3: 1: 1$ with absorbance maxima at 0.981 and ratio of terpolyester $B$ was $0.4: 1: 1$ with 0.875 . The UV- Vis spectroscopy study indicates that both the terpolyesters $A$ and $B$ have transition due to carbonyl chromophore present in the structure. It shows there is a transition in $\mathrm{nm}^{*}$.

\section{${ }^{1} \mathrm{H}-\mathrm{NMR}$ (nuclear Magnetic Resonance Spectroscopy) Film formation}

The produced terpolyester film was blended with Poly (butylene terephthalate) i.e. PBT with different ratios (Terpolyester: PBT- 6:4, 7:3, and 8:3). Out of which 7:3 ratio blend was selected for further processing. The above blend exhibited good pliability for casting (Fig. 6 \& 7).

\section{Physical testing of packaging film Tensile Strength}

The tensile strength of the developed biodegradable packaging material was performed using tensile strength tester (ASTM). It was found that terpolyester B film had higher percentage (8.7 MPa) of lactic acid, there by indicating high tensile strength of the polymer (Table 9).

\section{Durometer hardness test (Shore-A) ASTM D 2240}

The Durometer hardness test was used for measuring the relative hardness of test material. The results indicated that the terpolyester A (LA:EG:PA 0.3:1:1) have shore A - 94 and terpolyester B $(0.4: 1: 1)$ have A-92. 
Rao, E. S. et al. / J. Appl. \& Nat. Sci. 13(1): 316 - 326 (2021)

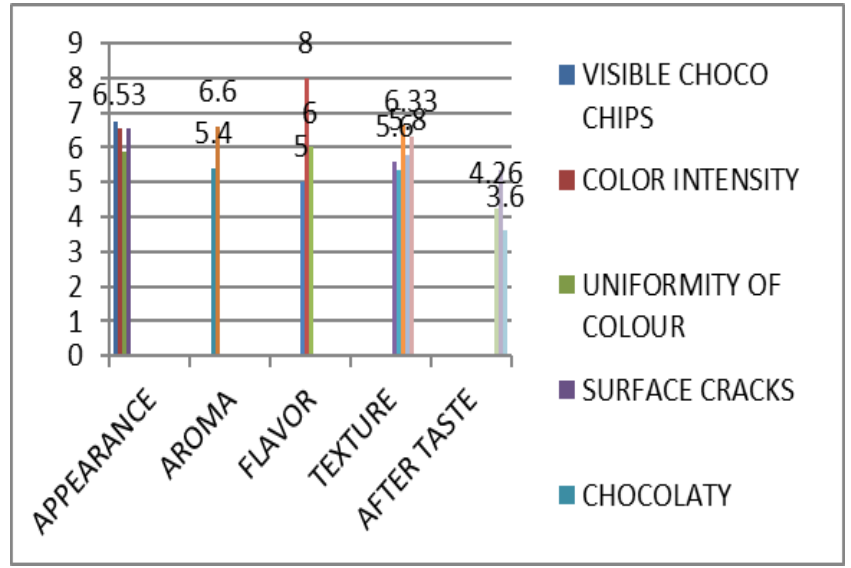

Fig. 4. Quantitative descriptive analysis of cookies.

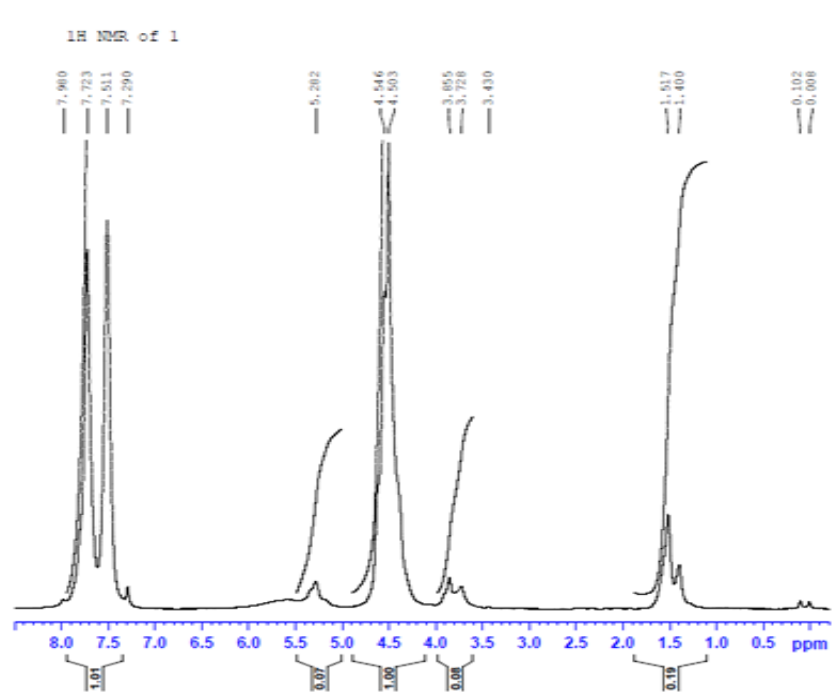

Fig. 6, 7. Showing ${ }^{1} H-N M R$ graph of the polymer.

Table 9. Tensile testing of synthesized terpolyester film.

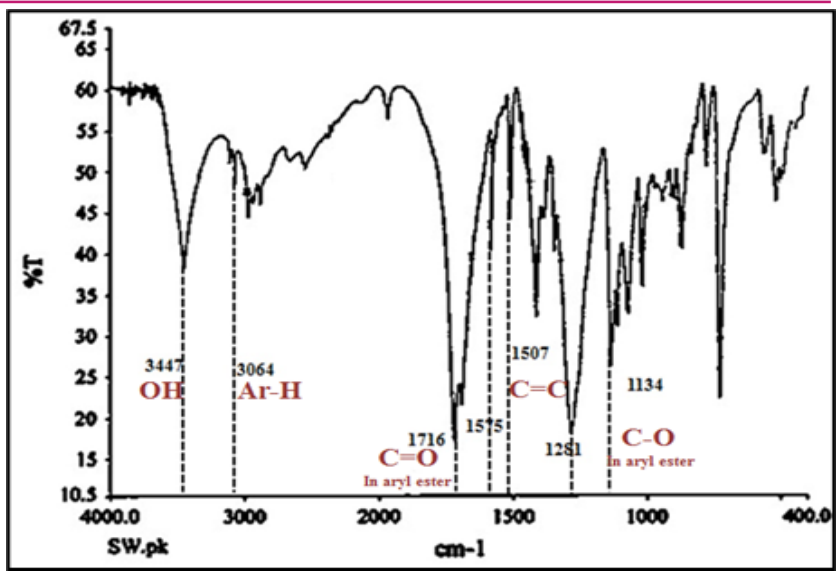

Fig. 5. FTIR spectra of terpolyester.

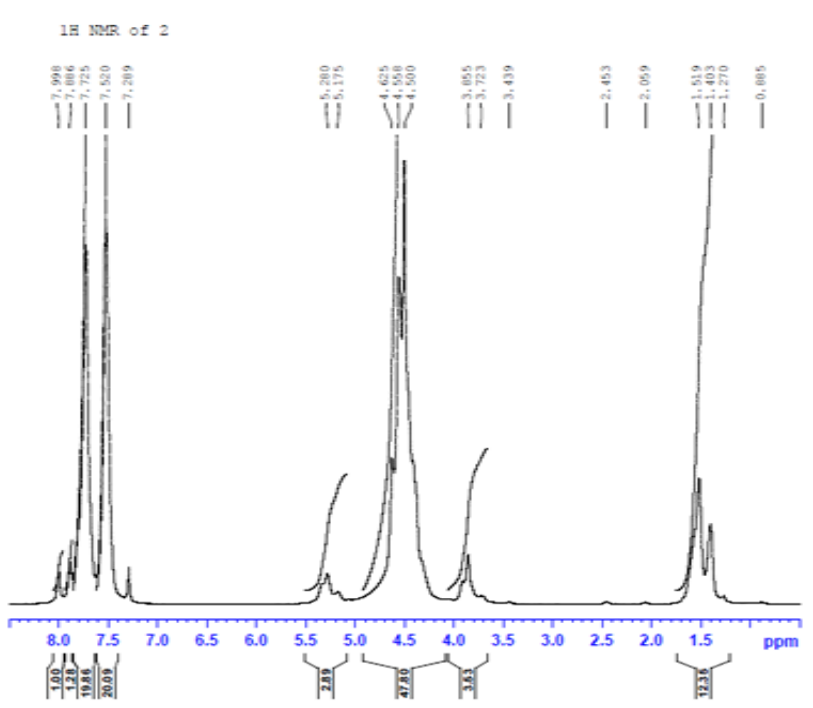

\begin{tabular}{lllll}
\hline Terpolyester & Ratio of LA:EG:PA & Peak Load (KG) & Break Load (KG) & Tensile Strength(MPa) \\
\hline A & $0.3: 1: 1$ & 4.85 & 4.85 & 7.6 \\
B & $0.4: 1: 1$ & 5.62 & 3.44 & 8.7 \\
\hline
\end{tabular}

Table 10. Biodegradation of terpolyester blended film by bacterial species (Bacilus).

\begin{tabular}{lllll}
\hline \multicolumn{5}{c}{ Terpolyester A(0.3:1:1) } \\
\hline Days & 15 & 30 & 45 & 60 \\
$\%$ Weight Loss & $11 \%$ & $23.34 \%$ & $42.67 \%$ & $62 \%$ \\
\hline & \multicolumn{5}{c}{ Terpolyester B(0.4:1:1) } \\
\hline Days & 15 & 30 & 45 & 60 \\
$\%$ Weight Loss & $11.31 \%$ & $27.77 \%$ & $45.46 \%$ & $68 \%$ \\
\hline
\end{tabular}

Both the polymers had optimum hardness indicating good mechanical strength of the packaging material. The standard hardness values are in the range of A- 90 -120 .

\section{Thermogravimatric analysis (TGA):}

This test indicates weight loss percentage during processing of the polymer resin. A packaging material that is light in weight is a desirable feature for packaging any commodity. The observed weight loss in terpolyester $A$ resin was $6.9 \%$ at $120^{\circ} \mathrm{C}$, as shown in Fig. 8. This is due to physiosorbed water on the resin, which is supported by the presence of three water molecules per unit of resin. In the TGA curve of terpolyester $B$ the weight loss was $4.4 \%$ at $120^{\circ} \mathrm{C}$ as in Fig. 9. This is due to physisorbed water on the resin, which supported the presence of only one water molecules per repeating unit of resin. 


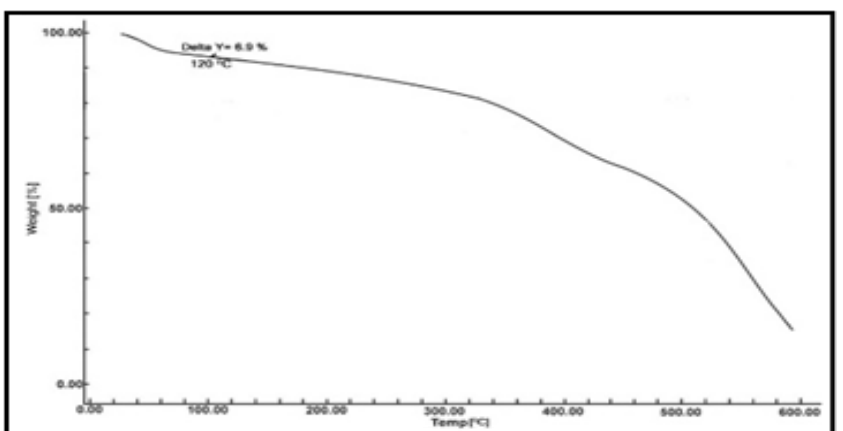

Fig. 8. TGA of terpolyester resin ratio 0.3:1:1.

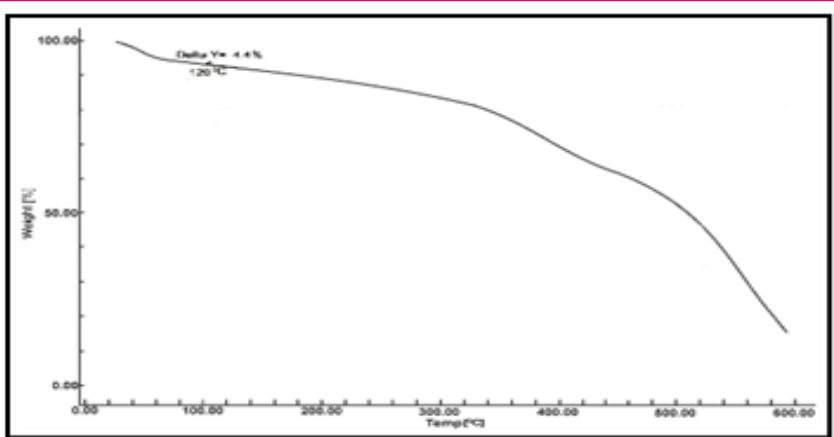

Fig. 9. TGA of terpolyester resin ratio 0.4:1:1.
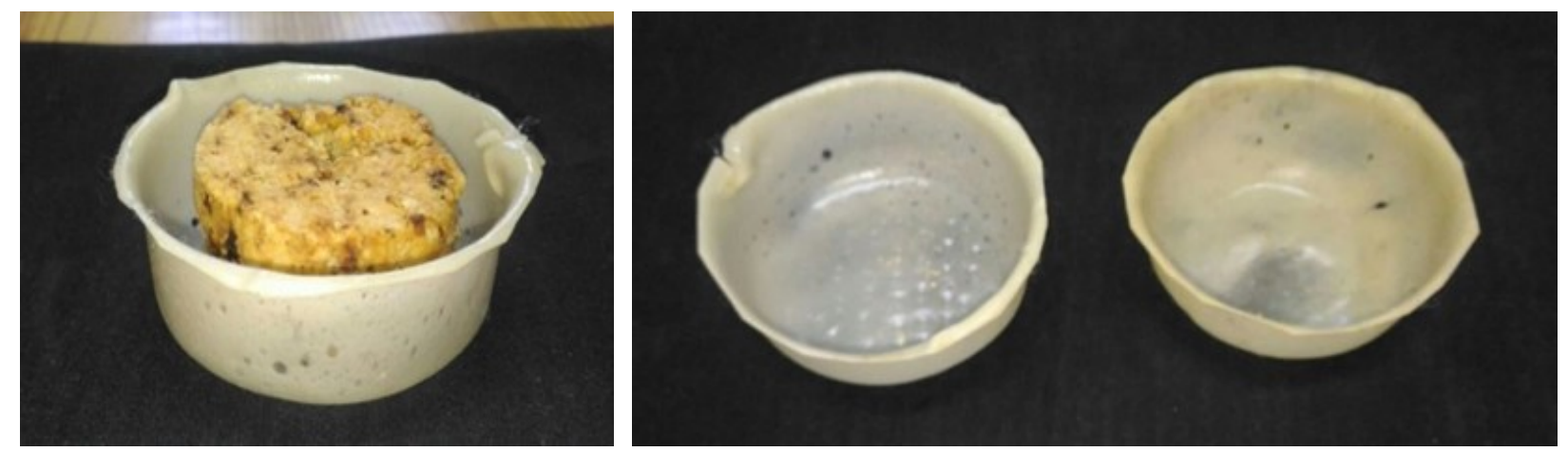

Fig. 10 \& 11. Biodegradable cups made with polyester film.

Table 11. Biodegradation of Terpolyester blended film by Fungul species (Aspergillus niger).

\begin{tabular}{lllll}
\hline \multicolumn{5}{c}{ Terpolyester A(0.3:1:1) } \\
\hline Days & 15 & 30 & 45 & 60 \\
$\%$ Weight Loss & $14.23 \%$ & $32.72 \%$ & $45.98 \%$ & $68 \%$ \\
\hline \multicolumn{5}{c}{ Terpolyester B(0.4:1:1) } \\
\hline Days & 15 & 30 & 45 & 60 \\
Weight Loss & $17.3 \%$ & $37.01 \%$ & $51.1 \%$ & $75.34 \%$ \\
\hline
\end{tabular}

\section{Test for biodegradability}

The synthesized terpolyester $A$ and $B$ blends of polymer films (0.3:1:1 and 0.4:1:1) were tested for their biodegradability by fungal species (Aspergillus niger) and Bacterial species (Bacillus). The biodegradation test seen in Tables 10 and 11 was done using bacterial and fungal strains of Bacillus and Aspergillus niger respectively for 60 days. It was observed that the polyester containing higher percentage of lactic acid undergoes greater degradation. The polymer is more susceptible to degradation by fungus than by bacteria. As time elapses, the degradation of polyester increases. The biodegradation also increases discolouration and brittleness in the polymer. It is observed that the biodegradability of Terpolyester B was higher i.e. $75 \%$ as compared to terpolyester A which was $68 \%$ as shown in Table 10.

\section{Preparation of primary packaging for cookies}

The synthesized terpolyester B film was used to manufacture cups, as shown in Fig. 10 and 11, due to its higher tensile strength as well as mechanical strength.
This was used as primary packaging for storing the cookies. The processing was done at an elevated temperature of $80^{\circ} \mathrm{C}$ with the technique of plug-assisted vacuum thermoforming by using Buckner flask as mould and beaker was used as a plug.

\section{Conclusion}

The sugar-free cookies with novel biodegradable packaging material were highly acceptable by the consumers and offered a healthy alternative to the diabetic population. It was low in glycemic index and rich in dietary fibre. The RDA for dietary fibre was $30 \mathrm{~g} / 2000 \mathrm{kcal}$ per day as per the Dietary Guidelines for Indians, 2020. One serving of these cookies would provide $1 / 4$ of the day's requirement. Thus, it is also an exceptionally good source of soluble fibre known for hypo-glycemic and hypo-cholestremic effects in humans. The developed biodegradable packaging material is one of its kind as it can be used to package food materials without affecting the taste, colour or flavour. It can be moulded in assorted shapes and sizes, providing a lot 
of aesthetic value to the commodities without compromising its printability and physical properties. Therefore, diabetic cookies and biodegradable packaging material offers huge potential as a functional food for the food industry after scaling it up

\section{ACKNOWLEDGEMENTS}

Authors express their sincere thanks to Bhaskaracharya College of Applied Sciences, University of Delhi, for providing the lab infrastructure, to Delhi University for funding the project and Dr S. Pandit, mentor and all the research associates, Preeti Tyagi, Nikita Chhabra, Aishwarya Rajendran, Saumya Sood, Vinay, Najiburrehman, Abhay Goel, Vipin Rai.

\section{Conflict of interest}

The authors declare that they have no conflict of interest.

\section{REFERENCES}

1. Aggarwal D., Sabikhi L., Sathish M. H. K., (2016). Formulation of reduced-calorie biscuits using artificial sweeteners and fat replacer with dairy-multigrain approach, NFS Journal, 2, 1-7.

2. AOAC (1998.) Official Method of Analysis. 15th Edition, Association of Official Analytical Chemists, Washington DC.

3. AOAC (2004). Approved laboratory methods, American Association of Cereal Chemists, Min.esota, USA.

4. AOAC (2005) Official method of Analysis. 18th Edition, Association of Officiating Analytical Chemists, Washington DC, Method 935.14 and 992.24.

5. ASTM (1996). Sensory Testing Methods, 2nd ed. ASTM, Manual 26 (E. Chamber and M.B. Wolf, eds.) pp. 54- 72, ASTM, West Conshohocken, PA.

6. Chattopadhyay, S., Raychaudhuri, U. and Chakraborty' R. (2014). Artificial sweeteners - A review. J. Food Sci. Tech., 51(4), 611-621.

7. Deshmukh S.D., Bhivagade N.M., (2019). Preparation of multigrain biscuits, Int. J. Food Sci and Techno., 4 (4), 610.

8. Faridi H., (1994) The Science of Cookie and Cracker Production. Academic Press. New York, 70-72.

9. Fontana, A.J. Jr (2000). Understanding the importance of water activity in food, Cereal Food World, 45(1), X-10.

10. Gao J., Han F., Guo X., Zeng X., Mason S.L., Brennan M. A., Brennan C. S., (2018). Image Analysis of the SugarReduced Muffin formulated with Stevianna or Inulin as a Sugar Replacer, Grain \& Oil Science and Technology, 1

\section{(2), 63-71}

11. Gnanavel, G., Mohana Jeya Valli, V. P., Thirumarimurugan M. and Kannadasan T., (2012). Degradation of Plastics Using Microorganisms, Int. J. Pharma. and Chem. Sci. V. 1(3), 1040-1043.

12. Handa, C., Gommer, S. and Siddhu, A. (2012). Physiochemical properties and sensory evaluation of fructooligosaccharide enriched cookies, J. Food Sci. Technol., 49(2), 192-199.

13. Jaemin, J., Fiaz H., Sangwon P., Soo-Jung K. and Jinhwan K., (2020) High Thermal Stability, High Tensile Strength, and Good Water Barrier Property of Terpolyester Containing Biobased Monomer for Next-Generation Smart Film Application: Synthesis and Characterization. Polymers, 12, 2458.

14. Jenkins, D.J.A., Kendall, C.W.C., Vuksan, V., Vidgen, E., Parker, T., Faulkner, D., Mehling, C.C., Garsetti, M., Testolin, G., Cunnane, S.C., Ryan, M.A. and Corey, P.N., (2002). Soluble fiber intake at a close approved by the US FDA for a claim of health benefits. Serum lipid risk factor cardiovascular disease assessed in a randomized controlled crossover trial, The Am. J. Clin. Nutr., 75, 834839.

15. Joshi SR. (2005) Management of Obese Indian Patient, Indian Journal of Obesity, I (1), 11-20.

16. Lindani K.N., Albert U.U., Enoch N. O., Rozli Z. and Isaac N.B., (2020). Environmental Impact of Food Packaging Materials: A Review of Contemporary Development from Conventional Plastics to Polylactic Acid Based Materials. Materials, 13, 4994.

17. Manley D. (2000). Technology of biscuits, crackers and cookies, 3. Woodhead Publishing.

18. Muller, R. J., Keeberg, I. and Deckwer, W. D., (2001). Biodegradation of polyesters containing aromatic constituents. J. Biotechnol., 86(2), 87-95.

19. Savitha Y.S., Indrani D., Prakash J., (2008) Effect of replacement of sugar with sucralose and maltodextrin on rheological characteristics of wheat flour dough and quality of soft dough biscuits, J. Texture Stud., 39, 605-616.

20. Stone, H., Sidel (1998). Quantitative Descriptive Analysis, developments, applications and the future, Food Technol., 52(8), 48-52.

21. Sudha, M.L., Vetrimani, R. and Leelavathi, K. (2007). Influence of fiber from different cereals on the rheological characteristics of wheat flour dough on biscuit quality, Food Chem., 100(4), 1365-1370.

22. Trevizian, Moraes and Bolini (2010). Different sweeteners in beverages prepared with instant and ground coffee: Ideal and equivalent sweetness. J. Sens. Stud., 25, 215-225.

23. Zoulas, E., Pinkis, S., Orepoulou, V. (2000). Effect of Sugar replacement by Polyols and acesulfame-K on properties of low fat cookies, J. Sci. Food \& Agri., 80(14), 20492056. 